\title{
SISTEM PENJUALAN SPARE PART TOKO AJM MOTOR MENGGUNAKAN CI BERBASIS ARSITEKTUR MVC
}

\author{
Ade Setiadi \\ Jurusan Magister Ilmu Komputer \\ Universitas Budi Luhur \\ Email: adesetiadi.ubl@gmail.com \\ Fifit Alfiah \\ Jurusan Magister Ilmu Komputer \\ Universitas Budi Luhur \\ Email: fifitalfiah.ubl@gmail.com
}

\begin{abstract}
ABSTRAK
Saat ini penggunaan komputer dan perangkat lunak semakin banyak hingga ke berbagai kehidupan, bahkan sampai pada bidang ekonomi. Sistem Informasi merupakan peranan sangat penting dalam kegiatan bisnis di suatu perusahaan. Toko AJM Motor bergerak dalam bidang penjualan spare part mobil dan masih menggunakan cara yang konvensional dalam mengolah data tentang transaksi penjualan, untuk itu Toko AJM Motor membutuhkan sistem informasi yang dapat menunjang kelancaran dalam melakukan transaksi penjualannya. Dalam dunia teknologi khususnya pemrograman saat ini, baik itu desktop maupun web base semakin marak pengerjaannya menggunakan framework dan salah satu framework berbasis PHP yang banyak digunakan yaitu CodeIgniter (CI). Framework CI memang dikembangkan untuk memudahkan dalam developing aplikasi dengan struktur file source code-nya menggunakan pendekatan arsitektur Models-Views-Controller (MVC) dan pemrograman berorientasi objek. Oleh sebab itu, kami menggunakan CI dalam developing aplikasi ini dengan metode Object Oriented Analysis and Design sebagai metode pengembangan system. Dengan dirancangnya sistem ini telah mempermudah pemilik toko dalam mengelola data pelanggan, supplier dan barang yang di beli dan di jual serta pembuatan laporan yang diperlukan untuk perhitungan penjualan dan dapat memberikan informasi yang berguna bagi pemilik toko secara up to date.
\end{abstract}

Kata kunci: codeigniter (CI), models-views-controller (MVC), object oriented, penjualan.

\begin{abstract}
Currently who using of computers and software increasingly to the various of life, even in the economic field. System Information is a very important role in business activities in a company. Shop AJM Motor is engaged in the sale of spare parts of cars and still use the conventional way in data processing of sales transactions, to the shop AJM Motor need information systems that can support the smooth running perform sales transactions. In the world of technology, especially programming at this time, be it a desktop or web base increasingly widespread use of the process framework and a PHP based framework that is widely used is CodeIgniter (CI). CI Framework was developed to facilitate in developing applications with source code file structure its approach Models architecture-ViewsController (MVC) and object-oriented programming. Therefore, we use the CI in developing this application with the method of Object Oriented Analysis and Design as a method of system development. With this system he designed, enables shop owners to manage the data of customers, suppliers and goods that are bought and sold as well as the preparation of reports required for the calculation of sales and can provide useful information for the store owners are up to date.
\end{abstract}

Keywords: codeigniter (CI), models-view-controller (MVC), object oriented, sales.

\section{PENDAHULUAN}

Cara Peran sistem informasi terhadap kemajuan organisasi sudah tidak diragukan lagi. Dengan dukungan sistem informasi yang baik maka sebuah perusahaan akan memiliki berbagai keunggulan kompetitif sehingga mampu bersaing dengan perusahaan lain. Pemanfaatan komputer sebagai alat kerja bantu, khususnya sebagai media pengolah data, baik yang berskala besar maupun skala kecil terus berkembang dengan pesat. Itu semua berkat kemajuan teknologi yang didorong oleh keinginan manusia untuk dapat melakukan pekerjaan yang cepat, tepat dan aman.

Bagi suatu perusahaan yang terus berkembang seperti pada AJM Auto Parts. Momentum Teknik sebagai suatu perusahaan yang bergerak di bidang penjualan sparepart mobil, tentunya memiki suatu sistem penjualan yang 
berguna untuk mempermudah pemilik dalam mengatasi masalah-masalah yang selalu timbul terutama dalam laporan barang masuk, laporan barang keluar serta laporan stok ketersediaan barang agar berjalan sesuai dengan prosedurnya sehingga hasilnya dapat dengan mudah untuk mengontrol data dan dalam pengambilan keputusan penjual.

\begin{tabular}{|c|c|c|c|c|c|c|c|}
\hline \multirow{2}{*}{ 10 } & \multirow{2}{*}{ Tosskname } & \multirow{2}{*}{ stort } & \multirow{2}{*}{ Finsh } & \multirow{2}{*}{ Durtion } & Aaralla & Noparal6 & 1402026 \\
\hline & & & & & \multicolumn{3}{|c|}{ 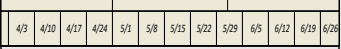 } \\
\hline & Pessispan & 4/1/2016 & $4 / 8 / 2016$ & 1w1d & ( & & \\
\hline 2 & Konsolidasi Tim & 4/12016 & $4 / 552016$ & 3d & a & & \\
\hline 3 & Pensusunan Korsep Procect & 44/42016 & 4/7/2016 & ${ }_{4 d}$ & $\mathbf{\square}$ & & \\
\hline \begin{tabular}{|l|}
4 \\
\end{tabular} & 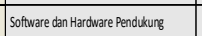 & $4 / 72016$ & 4/8/2016 & $2 \mathrm{~d}$ & I & & \\
\hline & Komunkasi Perencramanan dan Penodelan & 4/12/2016 & 5/92016 & $4 w$ & E & 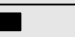 & \\
\hline 6 & Konsultas id nn pengurnoulan data awal & 4/12/2/2016 & $4 / 152016$ & ${ }_{4 d}$ & 口 & & \\
\hline & 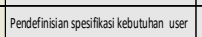 & 4/1/4/2016 & 4/18/2016 & $3 \mathrm{~d}$ & a & & \\
\hline 8 & 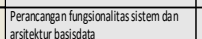 & 4/18/2016 & 5/2/2016 & 2N1d & & & \\
\hline 9 & \begin{tabular}{|l|} 
Menbuat model sistem \\
\end{tabular} & 4/20/2016 & $5 / 42016$ & 2urid & & & \\
\hline${ }_{10}$ & 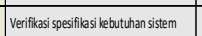 & $5 / 6 / 2016$ & 5192016 & $2 \mathrm{~d}$ & & [ & \\
\hline 11 & Development dan Pergyilan & $5 / 5252016$ & 5/3/2/2016 & $3 w 4 d$ & & & \\
\hline 12 & Datbase & $5 / 525016$ & 5/242012016 & 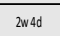 & & $\bar{E}$ & \\
\hline 13 & Tramplab (antaramuka) Sistem & $5 / 62016$ & 5//5/2016 & $2 v 4 \mathrm{dd}$ & & - & \\
\hline 14 & \begin{tabular}{|l} 
Perrogamann nungsionalitas \\
\end{tabular} & $5 / 92016$ & 5/26/2016 & $2 v 4 d$ & & — & \\
\hline 15 & \begin{tabular}{|l|} 
Pergyiun fungrs intemal \\
\end{tabular} & $5 / 13 / 2016$ & 5/27/2016 & 2uld & & $\square$ & \\
\hline 16 & 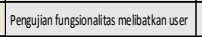 & 5/13/2/2016 & 5/30/2016 & $2 \mathrm{n} 2 \mathrm{~d}$ & & E & \\
\hline 17 & 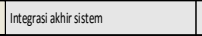 & $5 / 30 / 2016$ & 5/3/2/2016 & $2 \mathrm{~d}$ & & & \\
\hline 18 & 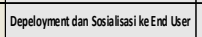 & 6/6/62016 & $6 / 1772016$ & $2 w$ & & & E \\
\hline 19 & \begin{tabular}{|l|} 
Perexananan Peatitian \\
\end{tabular} & $66 / 62016$ & $618 / 2016$ & 3d & & & प \\
\hline 20 & 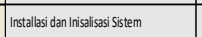 & $6 / 7 / 2016$ & 6/9/2016 & $3 d$ & & & 匹 \\
\hline 2 & Peryusunan Panduan Manual Apliksi & $66 / 82016$ & $6 / 10 / 2016$ & $3 \mathrm{~d}$ & & & $\bar{\square}$ \\
\hline 2 & 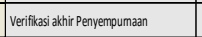 & 6192016 & $6 / 13 / 2016$ & $3 \mathrm{~d}$ & & & [ \\
\hline 23 & 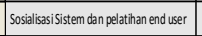 & $6 / 13 / 2016$ & 6/16/201616 & $4 \mathrm{~d}$ & & & [ \\
\hline & Penpusuran dan Penverahan Laporan & 4/1/2016 & $71 / 22016$ & ${ }_{13 w_{10}^{1 d}}$ & & & \\
\hline & lapronanalal & 44/42016 & $4(62016$ & $3 \mathrm{~d}$ & $\square$ & & \\
\hline & upporan Eekala & 5/13/2/2016 & $5 / 30 / 2016$ & $2 \mathrm{n} 2 \mathrm{~d}$ & & E & \\
\hline 27 & lappran Athir & $66 / 282016$ & $6 / 302 / 2016$ & $3 \mathrm{~d}$ & & & 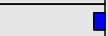 \\
\hline & 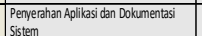 & $6 / 28282016$ & $6 / 30 / 2016$ & 3d & & & $\pi$ \\
\hline & Presentasi & 4/1/2016 & $71 / 2016$ & ${ }_{13}^{13} 1 \mathrm{~d}$ & & & \\
\hline 30 & \begin{tabular}{|l|} 
Presentasi Anal \\
\end{tabular} & 4/42016 & $46 / 62016$ & $3 \mathrm{~d}$ & $\square$ & & \\
\hline 31 & Presenansis Progers berkala & 5/12/2016 & 5/2/2/2016 & 2nv2d & & E & \\
\hline & Presentasis Ahtir & $6 / 28282016$ & $6 / 30 / 2016$ & $3 \mathrm{~d}$ & & & I \\
\hline
\end{tabular}

\section{Gambar 1. Gantt Chart}

Diagram perencanaan yang digunakan untuk penjadwalan sumber daya dan alokasi waktu dalam pengembangan system. Gantt Chart juga dapat membantu penggunanya untuk memastikan bahwa semua kegiatan telah direncakan, urutan kinerja telah diperhitungkan, perkiraan waktu kegiatan telah tercatat, dan keseluruhan waktu proyek telah dibuat [1].

Program kerja yang akan dilakukan oleh tim pengembang sistem dalam proyek ini disesuaikan dengan metodologi RAD (Rapid Application Development) menggunakan prototyping. Dalam pengembangan sistem informasi pun khususnya berbasis website saat ini sudah menggunakan konsep MVC (Model View Controller) yang membuat para developer (pembangun aplikasi) menjadi mudah dan penulisan source code yang menjadi lebih rapi sehingga mudah untuk kegiatan maintenance dan pengembangan. Konsep tersebut dikembangkan atas dasar OOP (Object Oriented Programming) atau Pemrograman Berorientasi Objek dan kemudian dikembangkan lagi dalam bentuk MVC Framework, Salah-satu MVC Framework yang populer digunakan saat ini adalah Framework CodeIgniter yang dikembangkan oleh Eliss Lab [9].

Dalam penelitian ini kami menggunakan teknik pengembangan prototyping, diterapkan dalam kerangka kerja penelitian tahap demi tahap dan menghasilkan sebuah website e-commerce ${ }^{[10]}$ berbentuk prototype berbasis OOP, dibangun menggunakan arsitektur MVC dan diterjemahkan menggunakan framework Codeigniter. Pada tahap analisis dan desain pada fase prototyping menggunakan alat analisis- desain Unified Modelling Language (UML), dan aplikasi diuji dengan menggunakan teknik black box untuk memastikan secara fungsional prototype dapat berjalan dengan baik. 


\section{METODOLOGI}

\subsection{Teknik Pengembangan Prototyping}

Metode prototyping [2] sering digunakan pada dunia nyata. Karena metode ini secara keseluruhan akan mengacu kepada kepuasan pengguna. Bisa dikatakan bahwa metode ini merupakan metode waterfall yang dilakukan secara berulang-ulang.

\subsection{Tahapan Metode Prototyping}

1) Pemilihan Fungsi. Mengacu pada pemilahan fungsi yang harus ditampilkan oleh prototyping. Pemilahan harus selalu dilakukan berdasarkan pada tugas-tugas yang relevan yang sesuai dengan contoh kasus yang akan diperagakan.

2) Penyusunan Sistem Informasi. Bertujuan memenuhi permintaan kebutuhan akan tersedianya prototype.

3) Evaluasi.

4) Penggunaan selanjutnya.

\subsection{Jenis-Jenis Prototyping}

1) Feasibility prototyping. Digunakan untuk menguji kelayakan dari teknologi yang akan digunakan untuk sistem informasi yang akan disusun.

2) Requirement prototyping. Digunakan untuk mengetahui kebutuhan aktivitas bisnis pengguna. Misalnya dalam sebuah perusahaan terdapat penggunadirektur, manajer, dan karyawan. Maka penggunaan sistem dapat dibedakan berdasarkan penggunatersebut sesuai dengan kebutuhannya.

3) Designprototyping. Digunakan untuk mendorong perancangan sistem informasi yang akan digunakan.

4) Implementation prototyping. Merupakan lanjutan dari rancangan protype, prototype ini langsung disusun sebagai suatu sistem informasi yang akan digunakan.

\subsection{Keunggulan Metode Prototyping}

1) Adanya komunikasi baik antara pengembang dengan pelanggan.

2) Pengembang dapat bekerja lebih baik untuk memenuhi kebutuhan pelanggan.

3) Pelanggan berperan aktif dalam pengembangan sistem.

4) Menghemat waktu dalam pengembangannya.

5) Penerapan lebih mudah karena pemakai akan mengetahui apa yang diharapkan.

\subsection{Kelemahan Metode Prototyping}

1) Kualitas sistem kurang baik karena hanya mengedepankan aspek kenyamanan pengguna.

2) Pengembang kadang-kadang menggunakan implementasi yang sembarangan.

3) Tidak mencerminkan proses perancangan yang baik.

\subsection{Metode Prototyping}

Metode Prototype merupakan suatu paradigma baru dalam metode pengembangan perangkat lunak dimana metode ini tidak hanya sekedar evolusi dalam dunia pengembangan perangkat lunak, tetapi juga merevolusi metode pengembangan perangkat lunak yang lama yaitu sistem sekuensial yang biasa dikenal dengan nama SDLC atau waterfall development model. Metodelogi prototyping ditunjukkan pada gambar 2. Tahapan dalam gambar 2 metodologi prototyping, yaitu:

1) Perencaan dan komunikasi terlebih dahulu yang dilakukan antara pelanggan dengan tim pemgembang perangkat lunak mengenai spesifikasi kebutuhan yang diinginkan.

2) Akan dilakukan perencanaan dan pemodelan secara cepat berupa rancangan cepat (quick design) dan kemudian akan memulai konstruksi pembuatan prototype.

3) Prototype kemudian akan diserahkan kepada para stakeholder untuk dilakukan evaluasi lebih lanjut sebelum diserahkan kepada para pembuat software.

4) Pembuatan software sesuai dengan prototype yang telah dievaluasi yang kemudian akan diserahkan kepada pelanggan.

5) Jika belum memenuhi kebutuhan dari pelanggan maka akan kembali ke proses awal sampai dengan kebutuhan dari pelanggan telah terpenuhi. 


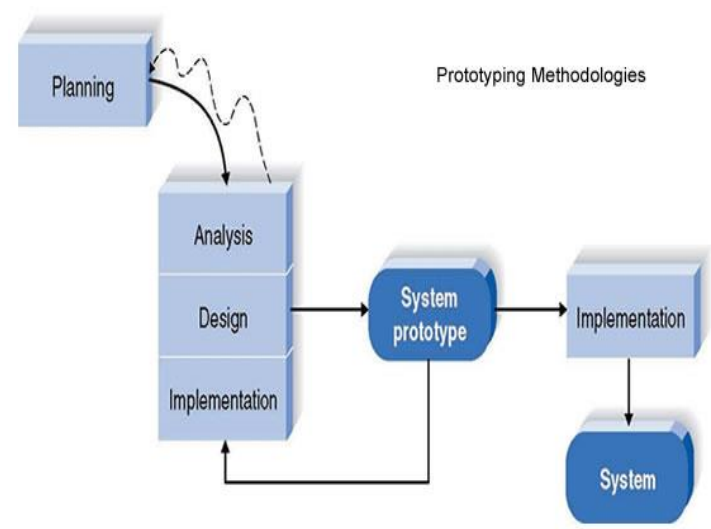

Gambar 2. Metodologi Prototyping [2]

\section{LANDASAN TEORI}

\subsection{CodeIgniter Framework}

CodeIgniter adalah framework aplikasi web yang open source untuk bahasa pemrograman PHP. CodeIgniter memiliki banyak fitur yang membuatnya berbeda dengan framework lainnya. Tidak seperti beberapa framework PHP lainnya, dokumentasi untuk framework ini sangat lengkap, yang mencakup seluruh aspek dalam framework. CoeIgniter juga mampu berjalan pada lingkungan Shared Hosting karena memiliki ukuran yang sangat kecil, namun memiliki kinerja yang sangat luar biasa [3].

Dari segi pemrograman, CodeIgniter kompatibel dengan PHP4 dan PHP5, sehingga akan berjalan dengan baik pada web host yang banyak dipakai saat ini. CodeIgniter menggunakan pola design ModelView-Controllwe $(M V C)$, yang merupakan cara untuk mengatur aplikasi web ke dalam 3 bagian yang berbeda, yaitu Model- lapisan abstraksi database, Views- file-file tampilan template depan, dan Controller- logika bisnis dari aplikasi. Pada intinya CodeIgniter juga membuat penggunaan ekstensif dari pola design Singleton. Maksudnya adalah cara untuk me-load class sehingga jika class itu di panggil dalam beberapa kali, kejadian yang sama pada class tersebut akan digunakan kembali. Hal ini sangat berguna dalam koneksi database, karena kita hanya ingin menggunakan satu koneksi setiap kali class itu digunakan.

CodeIgniter dikembangkan oleh Rick Ellis, dengan versi awal yang dirilis pada tanggal 28 februari 2006. Dari tahun itulah hingga sekarang telah muncul banyak versi Codelgniter yang terus berkembang dengan penambahan fitur baru dari sebelumnya. Bagaimana suatu proses data mengalir pada system yang menggunakan CodeIgniter Framework dapat diilustrasikan pada gambar berikut:

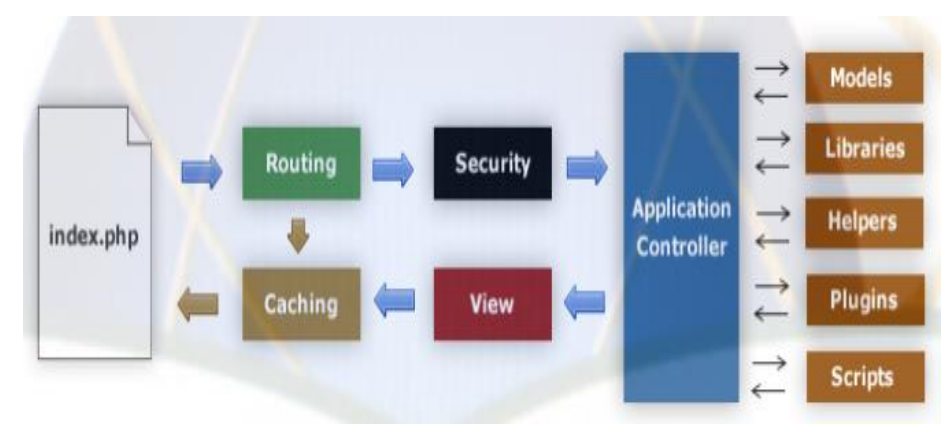

Gambar 3. Application Flow Chart CodeIgniter FrameWork [9]

Keterangan:

1) Index.php berfungsi sebagai front controller, menginisialisasi base resource untuk menjalankan CodeIgniter.

2) Router memeriksa HTTP request untuk memecahkan apa yang harus dilakukan dengannya.

3) Jika Cache aktif, maka hasilnya akan langsung dikirimkan ke browser dengan mengabaikan aliran data normal.

4) Security, sebelum controller dimuat HTTP request dan data yang dikirmkan user akan difilter untuk keamanan. 
5) Controller, memuat model, core libraries, plugins, helpers, dan semua resource yang diperlukan untuk memproses request.

6) Akhirnya view yang dihasilkan akan dikirim ke browser. Jika cache aktif, maka view akan disimpan sebagai cache dahulu sehingga pada request berikutnya langsung ditampilkan.

\subsection{MVC (Model View Controller)}

Model-View-Control (MVC) pertama kali diperkenalkan peneliti Xerox PARC yang bekerja pada bahasa pemrograman Smalltalk di akhir 1970-an dan awal 1980-an. Smalltalk adalah bahasa pemrograman yang berorientasi objek, bertipe dinamis, dan reflektif. Smalltalk pertama kali digunakan dalam pembelajaran edukasi dan hal ini berbeda dari data mainframe dan struktur control dalam program Smalltalk yang terlibat pada Windowed User Interfaces, konsep pemrograman berorientasi objek, pengantar pesan antara komponen-komponen objek, dan kemampuan untuk memonitor dan memodifikasi struktur dan perilakunya sendiri [3].

MVC merupakan sebuah pattern atau teknik pemrograman yang memisahkan antar pengembang aplikasi berdasarkan komponen utama pada sebuah aplikasi, seperti manipulasi data, user interface dan bagian yang menjadi kontrol aplikasi [4].

Secara sederhana dapat dikatakan bahwa antara desain dan proses data berada pada tempat yang terpisah. Saat ini $M V C$ merupakan suatu konsep yang cukup populer dalam pembangunan aplikasi web, yang berawal pada bahasa Smalltalk.

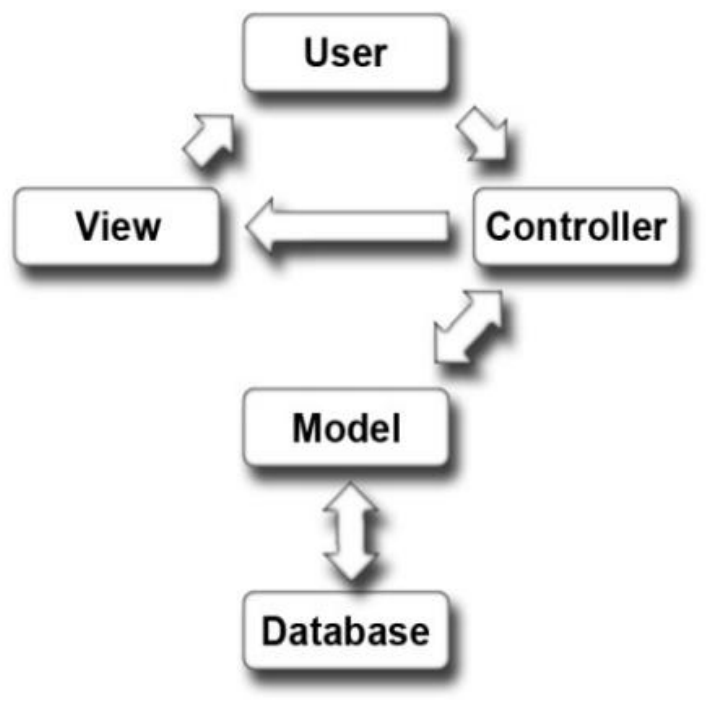

Gambar 4. Model-View-Contro [11]

Terdapat tiga jenis komponen yang membangun suatu MVC pattern yang terdapat pada gambar 4, yaitu:

1) Model- Model berhubungan dengan data dan interaksi ke database atau webservice. Model juga mempresentasikan struktur data dari aplikasi yang bisa berupa basis data maupun data lain, misalnya dalam bentuk file teks, XML maupun webservice. Biasanya didalam model akan berisi class dan fungsi untuk melakukan manipulasi data seperti insert, update, delete dan search, namun tidak dapat berhubungan dengan bagian view secara langsung, aplikasi website biasanya menggunakan database untuk menyimpan data, oleh karena itu model biasanya akan berhubungan dengan perintah-perintah query $S Q L$.

2) View-View berhubungan dengan segala sesuatu yang akan ditempatkan ke end-user, biasa berupa halaman web, RSS, Javascript dan lain-lain. Programmer harus menghindari adanya logika pemrosesan data di view. Di dalam view hanya berisi variabel-variabel yang berisi data yang siap ditampilkan. View dapat dikatakan sebagai halaman website yang dibuat menggunakan HTML dengan bantuan CSS, Javascript dan Jquery. Didalam view juga harus dihindari adanya kode untuk melakukan koneksi ke database. View hanya dikhususkan untuk menampilkan datadata hasil dari model dan controller. Bagian ini tidak memiliki akses secara langsung terhadap bagian model.

3) Controller-Controller merupakan penghubung antara model dan view. Didalam controller inilah terdapat class dan fungsi-fungsi yang memproses permintaan dari view kedalam struktur data didalam model. Controller juga tidak boleh berisi kode untuk mengakses basis data. Tugas 
controller adalah menyediakan berbagai variabel yang akan ditampilkan di view, memanggil model untuk melakukan akses ke database, menyediakan validasi atau pengecekan terhadap input.

\subsection{Pemrograman Beorientasi Objek}

Metodologi berorientasi objek adalah suatu strategi pembangunan perangkat lunak yang mengorganisasikan perangkat lunak sebagai kumpulan objek yang berisi data dan operasi yang diberlakukan terhadapnya [5]. Keuntungan menggunakan metodologi berorientasi objek adalah sebagai berikut:

1) Meningkatkan produktivitas, karena kelas dan objek yan ditemukan dalam suatu masalah masih dapat dipakai ulang untuk masalah lainnya yang melibatkan objek tersebut (reuseable)

2) Kecepatan pengembangan, karena sistem yang dibangun dengan baik dan benar pada saat analisis dan perancangan akan menyebabkan berkurangnya kesalahan pada saat pengolahan.

3) Kemudahan pemeliharaan, Karena dengan model objek, pola-pola yang cenderung tetap dan stabil dapat dipisahkan dan pola-pola yang mungkin sering berubah-ubah.

4) Konsistensi, karena sifat pewarisan dan penggunaan notasi yang sama pada saat analisis, perancangan maupun pengkodean.

5) Kualitas perangkat lunak, karena pendekatan pengembangan lebih dekat dengan dunia nyata dan adanya konsistensi pada saat pengembangannya, perangkat lunak yang dihasilkan akan mampu memenuhi kebutuhan pemakai serta mempunyai sedikit kesalahan. Beberapa contoh bahasa pemrograman yang mendukung pemrograman berorientasi objek: bahasa pemrograman Smalltalk, Eiffel, C++, PHP, Java.

\subsection{MYSQL}

MySQL merupakan database yang paling digemari dikalangan programmer website, dengan alasan bahwa program ini merupakan database yang sangat kuat dan cukup stabil untuk digunakan sebagai media penyimpanan data. Sebagai sebuah database server yang mampu untuk memanajemen database dengan baik, MySQL terhitung merupakan database yang paling digemari dan paling banyak digunakan dibanding database lainya [6].

\section{PEMBAHASAN}

\subsection{Analisis Perancangan Sistem}

Analisis berorientasi objek atau Object Oriented Analysis (OOA) adalah tahapan untuk menganalisis spesifikasi atau kebutuhan akan sistem yang akan dibangun dengan konsep berorientasi objek OOA biasanya menggunakan kartu CRC (Component, Responsibility, Collaborator) untuk membangun kelaskelas yang akan digunakan atau menggunakan UML (Unified Modeling Language) pada bagian diagram use case, diagram kelas, dan diagram objek [5].

Pemodelan berorientasi objek biasanya dituangkan dalam dokumentasi perangkat lunak dengan menggunakan perangkat pemodelan berorientasi objek, diantaranya adalah UML. Kendala dan permasalahan pembangunan sistem berorientasi objek biasanya dapat dikenali dalam tahap ini. OOA dan OOD dalam proses yang berulang-ulang seringnya memiliki batasan yang samar, sehingga terdapat dua tahapan yang sering juga disebut OOAD (Object Oriented Analysis and Design) atau dalam bahasa Indonesia berarti Analisis dan desain berorientasi objek.

\subsubsection{Kebutuhan Fungsional (Functional Requirements)}

Kebutuhan fungsional adalah jenis kebutuhan yang berisi proses-proses apa saja yang nantinya akan dilakukan oleh sistem. Sistem harus sesuai, baik dari segi perangkat lunak maupun perangkat keras untuk memudahkan user:

1) Mengelola otoritas login atau passcode, yaitu data passcode yang dimasukan oleh seller/admin dengan benar, dan selanjutnya memilih menu untuk malakukan aktifitas pekerjaan,

2) Mengelola input, edit dan delete untuk customer dan supplier.

3) Mengelola barang yang masuk ke toko melalui pembelian dari supplier, mengelola barang yang keluar dari toko karena adanya transaksi penjualan barang kepada customer.

4) Mengelola system untuk menyediakan report, seperti report produk masuk, report produk keluar dan report stok produk untuk dihasilkan tiap bulannya. 
5) Menyediakan fungsi logout.

\subsubsection{Kebutuhan Non-Fungsional (Non-Functional Requirements)}

Kebutuhan Non Fungsional adalah jenis kebutuhan yang berupa property perilaku yang dimiliki oleh sistem, yang meliputi teknologi, operasional, kinerja pegawai, serta keamanan dalam perusahaan. Bisa berupa:

1) Sistem yang dibuat lebih bersahabat (user friendly) untuk tampilan maupun kemudahan pengolahan data.

2) Sistem yang digunakan harus kompatibel, baik dari perangkat lunak (software) maupun perangkat keras (hardware) agar memudahkan admin dalam pengolahan data.

\subsection{Unified Modeling Language}

Unified Modeling Language (UML) adalah sebuah bahasa untuk menetukan, visualisasi, kontruksi, dan mendokumentasikan artifact (bagian dari informasi yang digunakan atau dihasilkan dalam suatu proses pembuatan perangkat lunak. Artifact dapat berupa model, deskripsi atau perangkat lunak) dari sistem perangkat lunak, seperti pada pemodelan bisnis dan sistem non perangkat lunak lainnya [7].

UML merupakan suatu kumpulan teknik terbaik yang telah terbukti sukses dalam memodelkan sistem yang besar dan kompleks. UML tidak hanya digunakan dalam proses pemodelan perangkat lunak, namun hampir dalam semua bidang yang membutuhkan pemodelan.

UML singkatan dari Unified Modeling Language yang berarti bahasa pemodelan standar [8]. Ketika kita membuat model menggunakan konsep UML ada aturan-aturan yang harus diikuti, bagaimana elemen pada model-model yang kita buat berhubungan satu dengan lainnya harus mengikuti standar yang ada. UML bukan hanya sekedar diagram, tetapi juga menceritakan konteksnya. UML diaplikasikan untuk maksud tertentu, biasanya antara lain untuk:

1) Merancang perangkat lunak.

2) Sarana komunikasi antara perangkat lunak dengan proses bisnis.

3) Menjabarkan sistem secara rinci untuk analisa dan mencari apa yang diperlukan sistem.

4) Mendokumentasi sistem yang ada, proses-proses dan organisasinya.

Jenis-jenis diagram yang dimiliki oleh UML adalah sebagai berikut:

1) Diagram kelas (class diagram) Diagram kelas adalah inti dari proses pemodelan objek. Baik forward engineering (proses perubahan model menjadi kode program) atau reverse engineering (proses perubahan kode program menjadi model) memanfaatkan diagram ini.

2) Diagram paket (package diagram)

3) Diagram use-case Diagram ini digunakan untuk mengorganisasi dan memodelkan perilaku suatu sistem yang dibutuhkan serta diharapkan pengguna. Use case menggambarkan external view dari sistem yang akan dibuat modelnya.

4) Diagram interaksi dan squence

5) Diagram komunikasi (communication diagram)

6) Diagram statechart (statechart diagram) Diagram statechart dalam UML kadang disebut dengan istilah diagram state machine. Diagram ini menggambarkan perilaku sistem perangkat lunak yang kita buat dan perilaku kelas, subsistem dan seluruh aplikasi. Selain itu diagram state machine bermanfaat juga untuk menyediakan cara yang baik dalam memodelkan komunikasi yang terjadi dengan entitas luar via protokol atau sistem dasarnya. UML memiliki dua state machine antara lain: (a) Behavioral State Machine, mesin ini digunakan untuk menunjukkan perilaku elemen yang dimodelkan, misalnya suatu objek, (b) Protocol State Machine, mesin ini digunakan untuk menunjukkan perilaku protokol.

7) Diagram aktivitas (activity diagram) Diagram aktifitas lebih memfokuskan diri pada eksekusi dan alur sistem dari pada bagaimana sistem itu dirakit. Diagram ini tidak hanya memodelkan software melainkan memodelkan model bisnis juga. Diagram aktivitas menunjukkan aktivitas sistem dalam bentuk kumpulan aksi-aksi.

8) Diagram komponen (component diagram)

9) Diagram deployment (deployment diagram) 


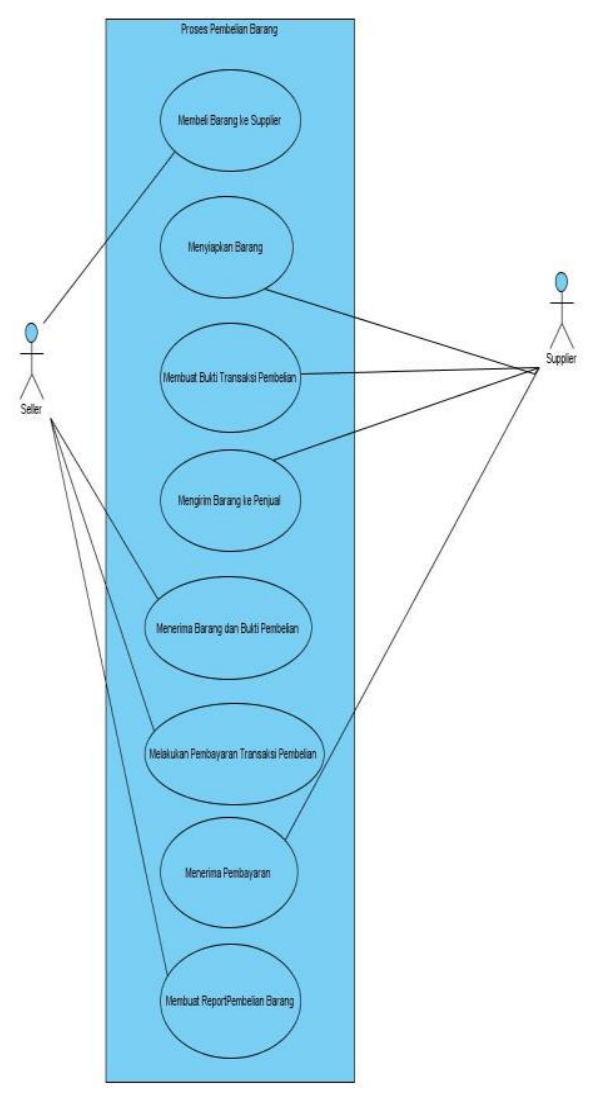

Gambar 5. Use Case Diagram Proses Pembelian Barang (Product In)

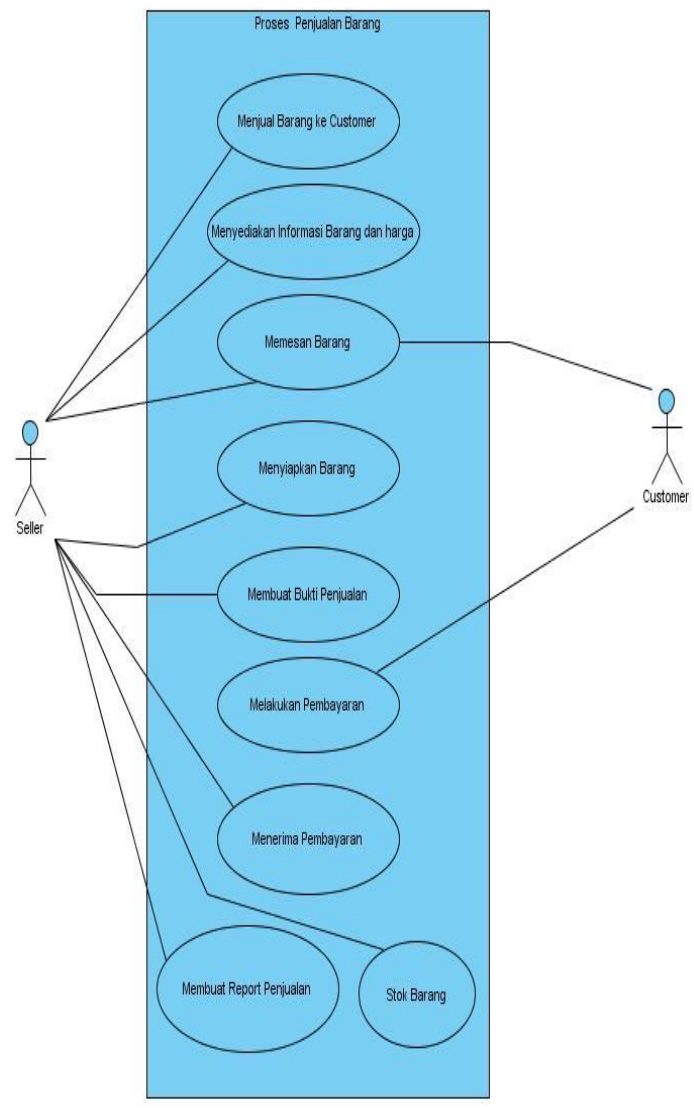

Gambar 6. Use Case Diagram Proses Penjualan Barang (Product Out) 


\subsection{Perancangan Sistem}

\subsubsection{Class Diagram}

Class diagram merupakan diagram yang menggambarkan jenis - jenis objek dalam sistem dengan berbagai macam relasi yang dimiliki. Class diagram menjelaskan hubungan antar class dalam sebuah system yang sedang dibuat dan bagaimana caranya agar class - class tersebut saling berkolaborasi untuk mencapai sebuah tujuan. Class diagram memiliki 3 area pokok (utama) yaitu: nama, atribut, dan operasi. Adapun class diagram Toko Spare Part AJM Motor dapat dilihat pada gambar dibawah ini:

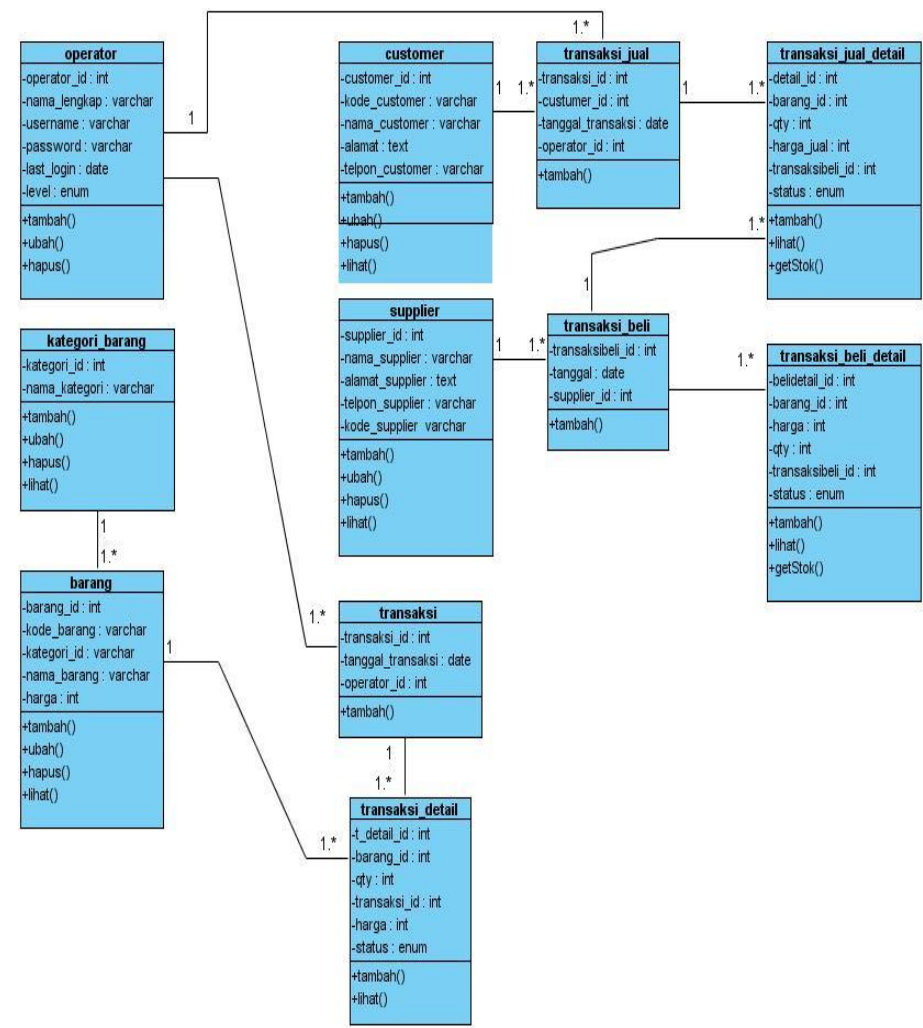

Gambar 7. Class Diagram Sistem

\subsubsection{Package Database}

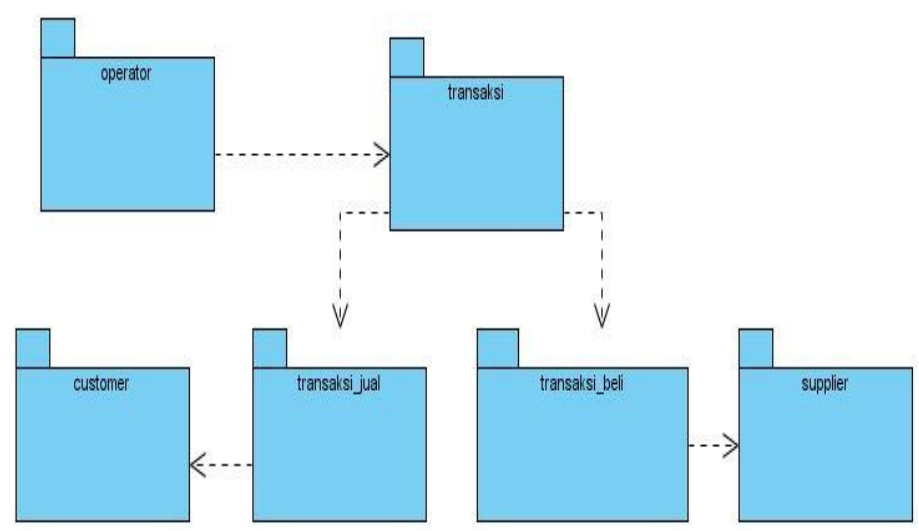

Gambar 8. Package Database 


\subsubsection{Rancangan User Interface}

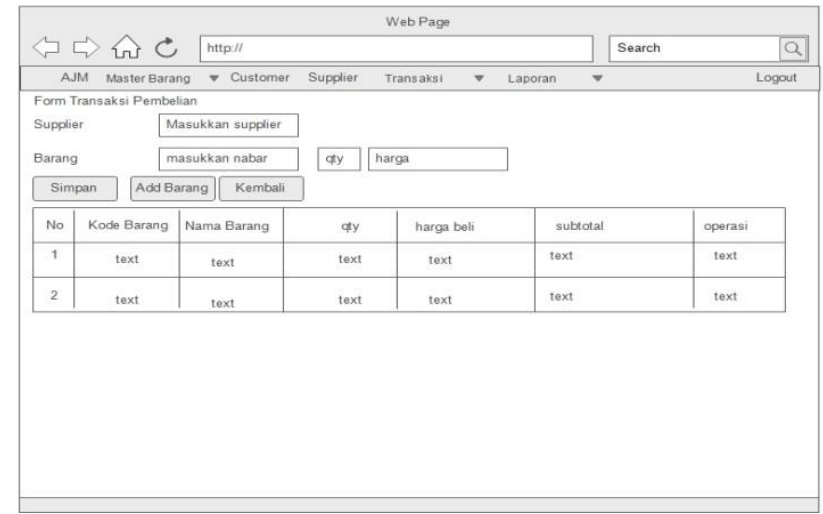

Gambar 9. Rancangan Tampilan Form Transaksi Pembelian

\section{HASIL PENELITIAN}

a) Halaman Login

Halaman ini dibuat merupakan tampilan pertama yang muncul pada saat program dijalankan, dimana pada form ini para pengguna atau operator akan diminta untuk memasukkan User ID beserta Password.

\section{Login Application}

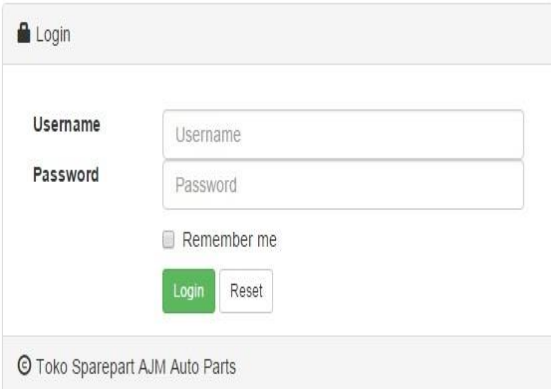

\section{Gambar 10. Halaman Login}

b) Menu Master Barang -> Data Barang

\begin{tabular}{|c|c|c|c|c|c|c|}
\hline \multicolumn{7}{|c|}{ Manajemen Data Barang } \\
\hline \multicolumn{7}{|c|}{ Trantat oata } \\
\hline No & Kode Barang & Nama Barng & & Kattegori Barang & Harga & Operasi \\
\hline 1 & BR014 & DAHATSU XEVA 1.0 Kampas Rem Belakang & & Sasis & 145000 & Eot Delete \\
\hline 2 & BR015 & DAHATSU XENA 1.0 Kampas Rem Depan & & Sasis & 145000 & Edit Delete \\
\hline 3 & BR016 & DAHATSU XENA 1.0 Koopling COVIer & & Sasis & 165000 & Eatit Delete \\
\hline 4 & BR017 & DAHATSU XENA 1.0 Kopling DisC & & Sasis & 240000 & Edt Delete \\
\hline 5 & BP018 & Casing Kuncikjang inova / Innova Yyaris Fortune & & Sasis & 85000 & Eot Delete \\
\hline 6 & BRo08 & AINEW COROL ALTISBUSI & & Mesin & 12500 & Eati Delete \\
\hline 7 & BROOS & AI NEW COROL ALTISFFiter Bensin & & Mesin & 286000 & Eort Delete \\
\hline
\end{tabular}

Gambar 11. Halaman Edit, Add and Delete Data Barang 
c) Menu Customer

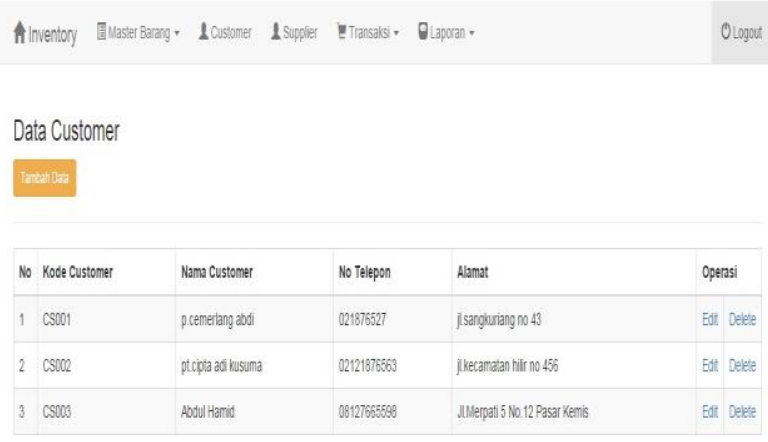

Gambar 12. Halaman Add, Edit and Delete Data Customer

d) Menu Supplier

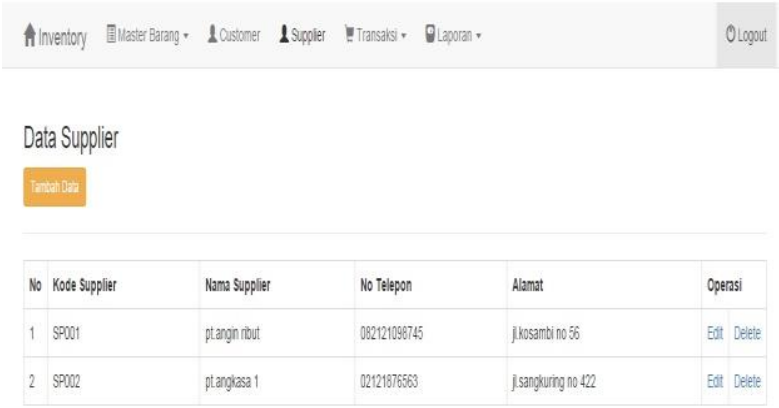

Gambar 13. Halaman Add, Edit and Delete Data Supplier

e) Menu transaksi Pembelian

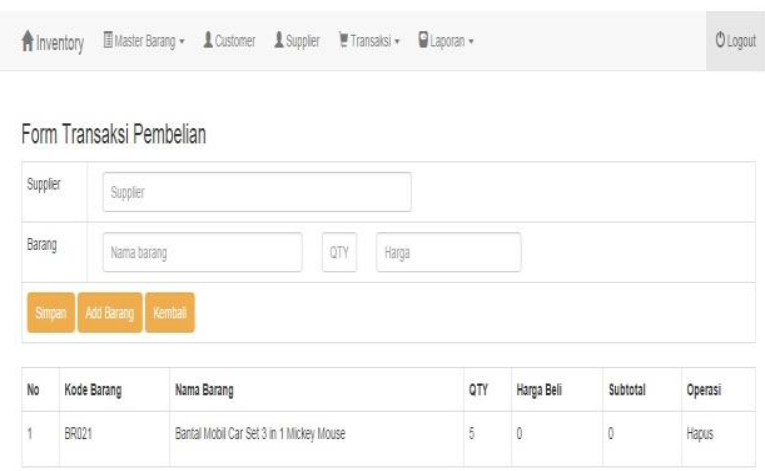

Gambar 14. Halaman Transaksi Pembelian Barang Ke Supplier

f) Menu Transaksi Penjualan

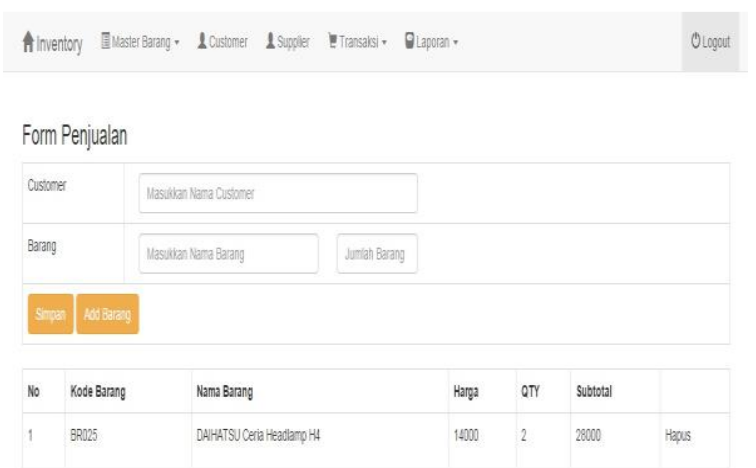

Gambar 15. Halaman Transaksi Penjualan Ke Customer 


\section{KESIMPULAN}

Berdasarkan dari penelitian atas sistem yang dilakukan oleh penulis pada toko spare part AJM motor, maka penulis menyimpulkan beberapa kesimpulan diantaranya adalah:

1) Bahwa dengan dirancangnya sistem ini akan mempermudah pemilik toko dalam mengelola data pelanggan, supplier dan barang yang di beli dan di jual serta pembuatan laporan yang diperlukan untuk perhitungan penjualan dan dapat memberikan informasi yang berguna bagi pemilik toko secara up to date.

2) Dengan adanya pembuatan sistem informasi penjualan pada AJM Motor, dari sistem yang masih konvensional menjadi sistem yang terkomputerisasi dapat digunakan dan dimengerti sesuai yang diharapkan terhadap pemilik toko AJM Motor.

3) Dengan adanya sistem informasi penjualan pada toko AJM Motor yang terkomputerisasi semua data dokumen penjualan yang sebelumnya masih konvensional sekarang menjadi tersimpan dengan baik dalam perangkat komputer.

4) Dalam membuat website system penjualan pada Toko AJM Motor ini lebih efisien dalam biaya, efektif dalam waktu yang tidak terlalu lama dan juga memudahkan peneliti karena menggunakan framework yang baik yaitu CodeIgniter dengan berbasis arsitektur MVC (Model-ViewControler).

5) Diharapkan kedepannya mampu mengembangkan atau melanjutkan dalam pembuatan sistem, dikarenaka terdapat menu yang belum diselesaikan dengan rapih dan belum sesuai dengan keinginan user.

\section{DAFTAR PUSTAKA}

[1] Heizer, J., and Render, B. (2005). Operations Management. $7^{\text {th }}$ Edition. New Jersey: Prentice-Hall.

[2] Pressman, R. (2002). Rekayasa Perangkat Lunak Pendekatan Praktisi. Yogyakarta: Andi.

[3] Andika, R. 2011. "Penerapan Ci (Codeigniter) Dalam Pengembangan System Informasi Manajemen Surat Dan Pengarsipan (Studi Kasus: Pt. Semen Padang)”. Jakarta: UIN Syarif Hidayatullah.

[4] Ardhana, Y K. (2013). Pemrograman Php: Codeigniter Black Box. Jakarta: Jasakom.

[5] Shalahuddin, M., dan Rosa, A S. (2011). Modul Pembelajaran Rekayasa Perangkat Lunak (Terstruktur Dan Berorientasi Objek). Bandung: Modula.

[6] Nugroho, B. (2004). Aplikasi Pemprograman Web Dinamis Dengan PHP Dan Mysql. Yogyakarta: Gava Media.

[7] Koespradono, S., dan Yuliana, R K. 2013. "Sistem Informasi Pengolahan Data Pertumbuhan Ekonomi Dan Ketimpangan Di Kabupaten Klaten (Tahun 2003-2012) Menggunakan Framework Codeigniter". ISSN:2338-6304 Institut Sains \& Teknologi Akprind Yogyakarta: Jurnal Script Vol. 1 No. 1 Desember 2013.

[8] Widodo, P P., dan Herlawati. (2011). Menggunakan Uml. Bandung: Informatika.

[9] Octafian, D T. 2015. "Web Multi E-Commerce Berbasis Framework Codeigniter. Jurnal Teknologi Dan Informatika (Teknomatika) Multi E-Commerce Berbasis Framework Codeigniter”. Vol. 5 No. 1 Jan 2015.

[10] Indah, I N. 2013. "Pembuatan Sistem Informasi Penjualan Pada Toko Sehat Jaya Elektronik". Pacitan: Indonesian Jurnal On Computer Science - Speed (Ijcss) 16 Fti Unsa Vol 10 No 2 - Mei 2013 - Ijcss.Unsa.Ac.Id. ISSN: 1979-9330 (Print) - 2088-0154 (Online) - 2088-0162 (Cdrom).

[11] Rosmala D., Ichwan M., dan Gandalisha M I. 2011. "Komparasi Framework Mvc (Codeigniter, Dan Cakephp) Pada Aplikasi Berbasis Web (Studikasus: Sistem Informasi Perwalian di Jurusan Informatika Institut Teknologi Nasional)". Institut Teknologi Nasional Bandung: Jurnal Informatika. No.2, Vol. 2, Mei - Agustus 2011. 